\title{
Adaptively constraining radar attenuation and temperature across the Thwaites Glacier catchment using bed echoes
}

\author{
DUSTIN M. SCHROEDER, ${ }^{1}$ HELENE SEROUSSI, ${ }^{2}$ WINNIE CHU, ${ }^{3}$ \\ DUNCAN A. YOUNG ${ }^{4}$ \\ ${ }^{1}$ Department of Geophysics, Stanford University, Stanford, CA, USA \\ ${ }^{2}$ Jet Propulsion Laboratory, California Institute of Technology, Pasadena, CA, USA \\ ${ }^{3}$ Lamont-Doherty Earth Observatory of Columbia University, Palisades, NY, USA \\ ${ }^{4}$ Institute for Geophysics, University of Texas at Austin, Austin, TX, USA \\ Correspondence: Dustin Schroeder <dustin.m.schroeder@stanford.edu>
}

\begin{abstract}
Englacial temperature is a major control on ice rheology and flow. However, it is difficult to measure at the glacier to ice-sheet scale. As a result, ice-sheet models must make assumptions about englacial temperature and rheology, which affect sea level projections. This is problematic if fundamental processes are not captured by models due to a lack of observationally constrained ice temperature values. Although radar sounding data have been exploited to constrain the temperature structure of the Greenland ice sheet using englacial layers, this approach is limited to areas and depths where these layers exist intact. In order to extend empirical radar-based temperature estimation beyond this limitation, we present a new technique for estimating englacial attenuation rates for the entire ice column using adaptive fitting of unfocused radar bed echoes based on the correlation of ice thickness and corrected bed echo power. We apply this technique to an airborne survey of Thwaites Glacier in West Antarctica and compare the results with temperatures and attenuation rates from a numerical ice-sheet model. We find that the estimated attenuation rates reproduce modelled patterns and values across the catchment with the greatest differences near steeply sloping bed topography.
\end{abstract}

KEYWORDS: attenuation, ice penetrating radar, temperature, thwaites glacier

\section{INTRODUCTION}

The behaviour, evolution and potential instability of the West Antarctic ice sheet is one of the greatest sources of uncertainty in projections of future sea level (Stocker and others, 2013). The Amundsen Sea Embayment is the most rapidly changing sector in West Antarctica, containing both Thwaites and Pine Island Glaciers, the two leading contributors to Antarctic mass loss (Chen and others, 2008; Pritchard and others, 2009; Mouginot and others, 2014; Sutterley and others, 2014). Although Pine Island Glacier has the larger contemporary negative mass balance, Thwaites Glacier is the only portion of Amundsen Sea sector with a landwardsloping bed that reaches from its current grounding position, on a series of bedrock highs, to the deep interior of the ice sheet (Holt and others, 2006; Tinto and Bell, 2011; Schroeder and others, 2014). This is a potentially unstable configuration (Weertman, 1974; Thomas and Bentley, 1978; Schoof, 2007; Tsai and others, 2015) in which retreat initialized at its grounding zone could spread to the rest of the glacier catchment in a feedback process that may already be under way (Joughin and others, 2014; Rignot and others, 2014). Because of this potential, efforts have been made to constrain projections of the rate and extent of such a retreat using numerical ice-sheet models (Parizek and others, 2013; Joughin and others, 2014; Pollard and others, 2015). However, these models include ice flow laws and rheology values that are temperature dependent (Engelhardt, 2004; Cuffey and Paterson, 2010) yet largely unconstrained by glacier-scale observations of ice sheet temperatures (MacGregor and others, 2015). As a result, poor knowledge of the englacial temperature structure of Thwaites Glacier may be a significant source of uncertainty in model-based projections of future sea-level contributions from the Amundsen Sea Embayment and West Antarctic ice sheet.

One of the most powerful and widely used geophysical tools for catchment-scale observation of subglacial and englacial ice-sheet properties is airborne radar sounding (Gudmandsen, 1971; Corr and others, 1993; Peters and others, 2005; MacGregor and others, 2007; Oswald and Gogineni, 2008; Carter and others, 2009; Dowdeswell and Evans, 2004; Wright and others, 2012; Schroeder and others, 2015; Young and others, 2016). Radar-sounding bed echo strengths are influenced by a combination of englacial and subglacial properties (Boithias, 1987; Peters and others, 2005; Matsuoka, 2011; MacGregor and others, 2013). Therefore, correction for englacial attenuation is required in order to make inferences about the material and geometric properties of the bed from basal reflectivity. Variations in radar-sounding bed-echo strength have long been used to constrain and correct for englacial attenuation in areas where the depth-averaged attenuation rate could be assumed to be constant (Robin and others, 1969; Winebrenner and others, 2003; Jacobel and others, 2009; Matsuoka and others, 2010; Barrella and others, 2011; Fujita and others, 2012; MacGregor and others, 2012) or to vary linearly with distance along flow (Schroeder and others, 2016). However, these assumptions can limit the utility of such approaches to areas far below the scale of a glacier catchment (Jacobel and others, 2010), making them 
unsuitable for observationally constraining larger-scale englacial temperature structure.

Recent work has demonstrated the use of radar reflections from englacial layers to constrain attenuation rates and temperatures as a function of depth within the upper portion of the Greenland ice sheet (MacGregor and others, 2015). This technique exploits the dependence of radar attenuation on ice temperature (Gudmandsen, 1971; Bogorodsky and others, 1985; Corr and others, 1993; Wolff and others, 1997; MacGregor and others, 2007) by assuming constant reflectivity values for internal layers (Drews and others, 2009; MacGregor and others, 2015). Although applicable at the ice-sheet scale, this approach requires extant, contiguous and undisturbed englacial layers, which excludes many fast-flowing and highly crevassed regions near grounding zones and shear margins as well as the deepest $\sim 20 \%$ of the ice column (MacGregor and others, 2015). It is these very regions, however, that can play a dominant role in ice-sheet dynamics and are likely to have the most heterogenous thermal signatures (Joughin and others, 2009; Matsuoka and others, 2012; Parizek and others, 2013). As a result, layer-based approaches can not be used to observe englacial temperatures in many of the areas most critical for ice-sheet modelling. To address this issue, we present a new radar-sounding analysis technique that uses unfocused bed echoes within an adaptive, empirical attenuation-fitting framework to provide catchment-scale estimates of englacial attenuation and temperature that can be applied to any radar-sounding system or survey orientation and are independent of the condition of englacial layers.

\section{METHODS}

Most existing techniques for constraining radar attenuation using bed echoes were developed to correct for rather than measure englacial attenuation (Jacobel and others, 2010; Matsuoka and others, 2012; Schroeder and others, 2016). As such, they either assume simplistic, constant or linearly varying attenuation rates for entire surveys (Jacobel and others, 2010; Schroeder and others, 2016) or rely on numerical ice-sheet models to predict attenuation rate values or gradients (Matsuoka and others, 2012; Jordan and others, 2016). While effective at improving estimates of basal reflectivity and therefore bed conditions, they do not resolve the pattern of englacial attenuation itself. In principle, improved spatial resolution could be achieved by fitting attenuation rates for sub-profile segments. In practice, however, such fitting requires sufficient variation in ice thickness and attenuation within a segment to accurately estimate the attenuation rate (Jacobel and others, 2010), setting an effective lower bound on segment size. Further complicating matters, this bound, which results from the trade-off between spatial (segment length) and radiometric (attenuation estimate) resolution, varies as a function of local topography, ice thickness and the attenuation rate itself. Therefore, the optimum fittingsegment length will vary across a survey so that areas with larger ice thickness relief are fit with higher spatial resolution and areas with less ice thickness relief are fit with sufficiently long segments to achieve comparable radiometric resolution. To achieve this, we present a simple, adaptive, attenuationfitting technique that can constrain spatial variations in the depth-averaged englacial attenuation rate and temperature at the glacier-catchment scale.

For radar sounding data, the geometrically-corrected bedecho power $\left(\left[P_{\mathrm{g}}\right]\right)_{\mathrm{dB}}$ is given by

$$
\left[P_{\mathrm{g}}\right]_{\mathrm{dB}}=[P]_{\mathrm{dB}}+2[2(h+d / \sqrt{\varepsilon})]_{\mathrm{dB}}
$$

where $[P]_{\mathrm{dB}}$ is the received bed-echo power, $h$ is the aircraft survey height above the surface, $d$ is the ice thickness, $\varepsilon$ is the real permittivity of ice and []$_{\mathrm{dB}}$ indicates power on a decibel scale (Matsuoka and others, 2012). This geometrically-corrected power is a function of instrument parameters $(S)$, basal reflectivity $(R)$, birefringence $(B)$ and two-way englacial losses $(L)$, so that

$$
\left[P_{\mathrm{g}}\right]_{\mathrm{dB}}=[S]_{\mathrm{dB}}+[R]_{\mathrm{dB}}-[S]_{\mathrm{dB}}-[L]_{\mathrm{dB}},
$$

where $[L]_{\mathrm{dB}}=2 d\langle N\rangle$ and $\langle N\rangle$ is the one-way depth-averaged attenuation rate (Matsuoka and others, 2012). Assuming that instrument parameters, reflectivity and birefringence are uncorrelated with ice thickness, the geometrically-corrected bed-echo power can be written as a linear function of thickness, so that

$$
\left[P_{\mathrm{g}}\right]_{\mathrm{dB}}=\left[P_{\mathrm{a}}\right]_{\mathrm{dB}}-2 d\langle\mathrm{~N}\rangle,
$$

where $P_{\mathrm{a}}$ is the attenuation-corrected bed-echo power, which includes the thickness-uncorrelated parameters. Then, for non-negligible values of $\langle N\rangle,\left[P_{\mathrm{g}}\right]_{\mathrm{dB}}$ and $d$ will be strongly anticorrelated. In the example profile (Fig. 1), this anticorrelation is easy to see in the ice thickness (Fig. 1c)
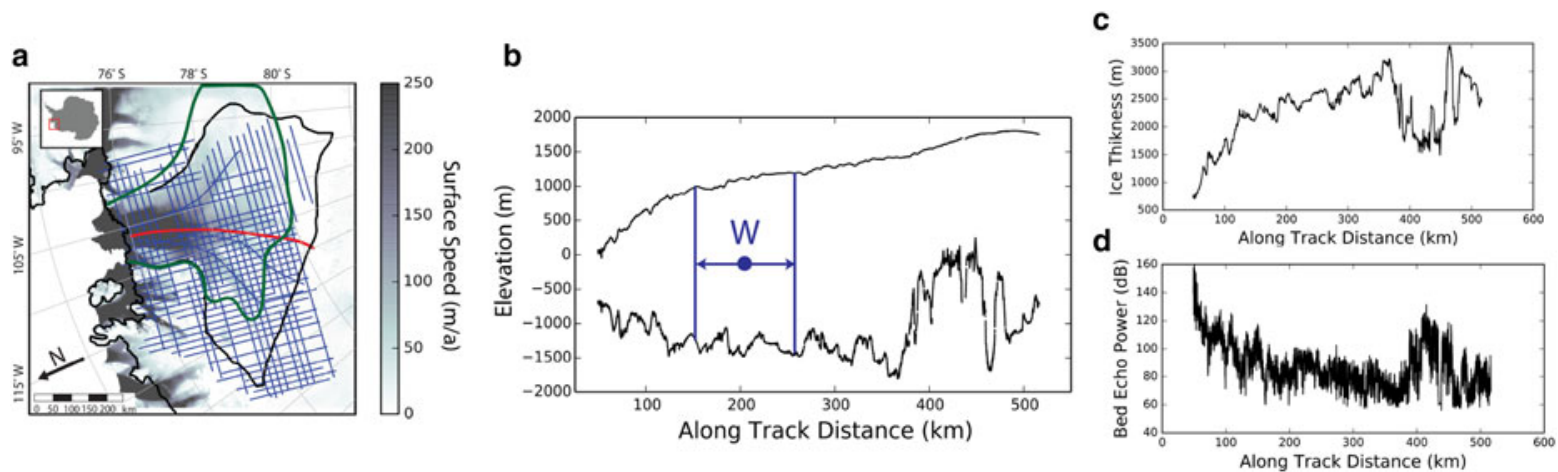

Fig. 1. (a) Airborne radar sounding survey (Holt and others, 2006) of the Thwaites Glacier catchment (black boundary) in the context of icesurface speed (Rignot and others, 2011). Green boundary indicates ISSM modelling domain. (b) Example profile 'THW/SJB2/DRP08a' (red line in A) showing the length (W) of an attenuation fitting segment. The (c) ice thickness and (d) geometrically-corrected bed echo power for the example profile. 
and geometrically-corrected bed-echo power (Fig. 1d) profiles. By contrast, if the attenuation rate $\langle N\rangle$ was known, the attenuation-corrected bed-echo power $\left(P_{\mathrm{a}}\right)$ could be calculated as

$$
\left[P_{\mathrm{a}}\right]_{\mathrm{dB}}=\left[P_{\mathrm{g}}\right]_{\mathrm{dB}}+2 d\langle N\rangle,
$$

resulting in a $\left[P_{\mathrm{a}}\right]_{\mathrm{dB}}$ profile that is uncorrelated with $d$. It is this difference in correlation behaviour between the corrected and uncorrected bed-echo power with ice thickness that we exploit to estimate the local englacial attenuation rate.

The attenuation-corrected bed echo power $\left(\left[P_{\mathrm{a}}\right]_{\mathrm{dB}}\right)$ and ice thickness $(d)$ have a correlation-coefficient magnitude (C) of

$$
C=\left|\frac{\left.\sum_{i=1}^{n}\left(d_{i}-\bar{d}\right)\left(\left[P_{\mathrm{a}}\right]_{\mathrm{dB}, i}-\overline{[P}_{\mathrm{a}}\right]_{\mathrm{dB}}\right)}{\left.\left.\sqrt{\sum_{i=1}^{n}\left(d_{i}-\bar{d}\right)^{2}} \sqrt{\sum_{i=1}^{n}\left(\left[P_{\mathrm{a}}\right]_{\mathrm{dB}, i}-\overline{\left[P_{\mathrm{a}}\right]}\right.}\right)_{\mathrm{dB}}\right)^{2}}\right|
$$

which will have a value closer to zero if corrected using the actual attenuation rate $(\langle N\rangle)$ and closer to one if corrected using a value of $\langle N\rangle$ that is either much larger or smaller than the actual value. This can be seen in Figure 2, which shows $C$ as a function of the attenuation rate used in calculating $P_{\mathrm{a}}$ for the example profile in Figure 1. Without attenuation correction $(\langle N\rangle=0), \quad\left[P_{\mathrm{a}}\right]_{\mathrm{dB}}=\left[P_{\mathrm{g}}\right]_{\mathrm{dB}}$ and the uncorrected correlation-coefficient magnitude $\left(C_{0}\right)$ is large $(\sim 0.8)$. As the attenuation-rate increases, the correlationcoefficient magnitude decreases to a minimum value of $C_{0}$ $(\sim 0)$ at an attenuation rate of $\left\langle N_{\mathrm{m}}\right\rangle$, which is the attenuation rate at the correlation minimum $\left(C_{m}\right)$ and our estimate for the local one-way depth-averaged attenuation rate. The value of $C$ once again increases for actuation-rate values greater than $\left\langle N_{\mathrm{m}}\right\rangle$. We characterize the radiometric resolution of our attenuation-rate estimate by the half width $\left(\left\langle N_{h}\right\rangle\right)$ of this correlation minimum that falls below a given correlation coefficient magnitude $\left(C_{\mathrm{w}}\right)$ (Fig. 2).

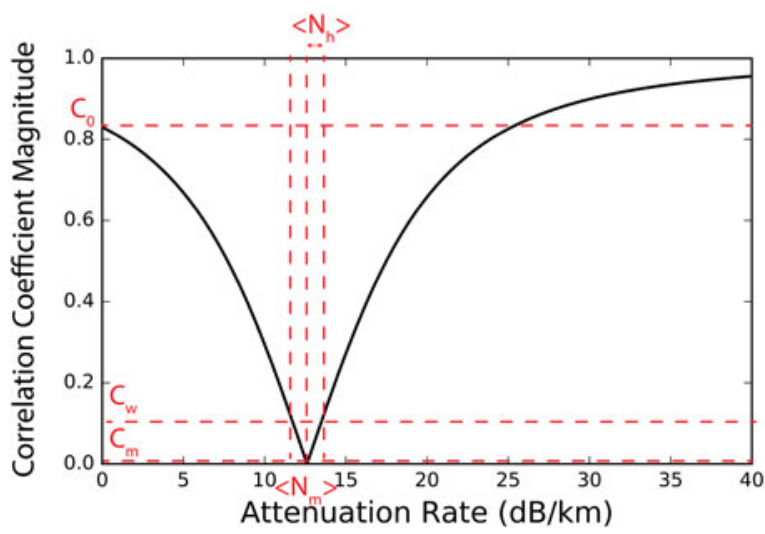

Fig. 2. Correlation coefficient as a function of attenuation-rate correction $\langle N\rangle$ for the example profile (Fig. 1). Magnitude of the correlation coefficient $(C)$ of ice thickness $(d)$ and attenuationcorrected bed echo $\left(P_{\mathrm{a}}\right)$ as a function of the attenuation rate $(\langle N\rangle)$ used in the correction. $C_{0}$ is the correlation coefficient magnitude without correction, $C_{m}$ is the minimum correlation coefficient magnitude, $\left\langle N_{m}\right\rangle$ is the attenuation rate that produced the minimum correlation coefficient magnitude, $C_{\mathrm{w}}$ is the correlation coefficient magnitude at which the width of the minimum is assessed, $\left\langle N_{h}\right\rangle$ is the half-width of the correlation coefficient minimum.
In order to resolve the pattern of englacial attenuation at the finest spatial resolution possible while maintaining a target radiometric resolution, we perform this correlation-based fitting on sub-profile segments (Fig. 1b) and increase the length of that segment $(W)$ until the target radiometric resolution is achieved (e.g. $\left\langle N_{\mathrm{h}}\right\rangle \leq 1 \mathrm{~dB} / \mathrm{km}$ for $C_{\mathrm{w}}=0.1$ ). This assumes that the thickness-correlated power-loss signal is an expression of englacial attenuation rather than basal conditions (MacGregor and others, 2013; Schroeder and others, 2016). We repeat this process for each location along a profile, discarding estimates for locations at which the target radiometric resolution can not be achieved. For the example profile in Figure 1, the resulting adaptively-fit attenuation rates (Fig. 3a) and fitting-segment lengths (Fig. 3b) show that, as expected, longer fitting segments occur in areas (e.g. along-track distances between 200 and $300 \mathrm{~km}$ ) with less ice thickness relief (Fig. 1b). In this adaptive fitting, we require that $\left\langle N_{h}\right\rangle \leq$ $1 \mathrm{~dB} / \mathrm{km}, C_{0} \geq 0.5$ and $C_{\mathrm{m}} \leq 0.01$ and use a $C_{\mathrm{w}}$ value of 0.1 (Fig. 2). Setting a minimum value on $C_{0}$ ensures that the window is long enough that there is an ice-thickness correlated attenuation signal that is meaningful to minimize. Setting a maximum value of $C_{m}$ ensures that a meaningful minimization has been achieved. Figure 4 shows values of $C_{0}(A), C_{m}(B)$, $\left\langle N_{h}\right\rangle(C)$ and $\left\langle N_{m}\right\rangle$ (D) as a function of fitting segment length and along-track distance for the example profile in Figure 1. We can see that the values of the estimated attenuation rate $\left(\left\langle N_{\mathrm{m}}\right\rangle\right.$, Fig. $\left.4 \mathrm{~d}\right)$ are most sensitive to $C_{0}$ (Fig. 4a). This is because the approach depends on having a depth-correlated attenuation signal to minimize. Segments that do not meet the minimum value for $C_{0}$ can lead to severe over- or underestimations due to fitting signals other than the attenuation rate. Figure 4 also shows that some locations along the profile can achieve the target radiometric resolution (Fig. 4c) using much smaller segment lengths than others. Taking advantage of this heterogeneity to resolve the finer-scale details of attenuation-rate patterns is a major reason for pursuing an adaptive fitting approach.

We applied this approach to an airborne radar-sounding dataset collected across the Thwaites Glacier catchment using the High Capability Airborne Radar Sounder (HiCARS) as part of the Airborne Geophysical survey of the Amundsen Sea Embayment (AGASEA) (Holt and others, 2006). These were processed using unfocused synthetic aperture radar for an along-track sampling rate of $4 \mathrm{~Hz}$ (Peters and others, 2005). In estimating the attenuation rates for this survey, we require that $C_{0} \geq 0.5, C_{m} \leq 0.01$ and $C_{\mathrm{w}}=0.1$ while setting the target radiometric resolution values of $\left\langle N_{h}\right\rangle \leq 1,2$ and $3 \mathrm{~dB} / \mathrm{km}$. This resulted in the estimated attenuation rate values shown in Figure 5 and the corresponding fitting-segment lengths shown in Figure 6 . The resulting mean $(\mu)$ and standard deviation $(\sigma)$ cross-over errors for each radiometric resolution are shown in Table 1. It is clear from Figures 4,5 and 6 as well as Table 1 that more restrictive target radiometric resolutions will produce estimates with lower errors but degraded spatial resolution and coverage (more locations are discarded for failing to achieve the required radiometric resolution). In contrast, less restrictive target radiometric resolutions will achieve better spatial resolution and coverage at the cost of larger errors. It is also clear from Figure 4 that, in our approach, larger attenuation-rate areas require more permissive radiometric resolutions in order to be resolved. Therefore, in practice, the choice of target $\left\langle N_{h}\right\rangle$ will depend on the glacier, region and process of interest. 

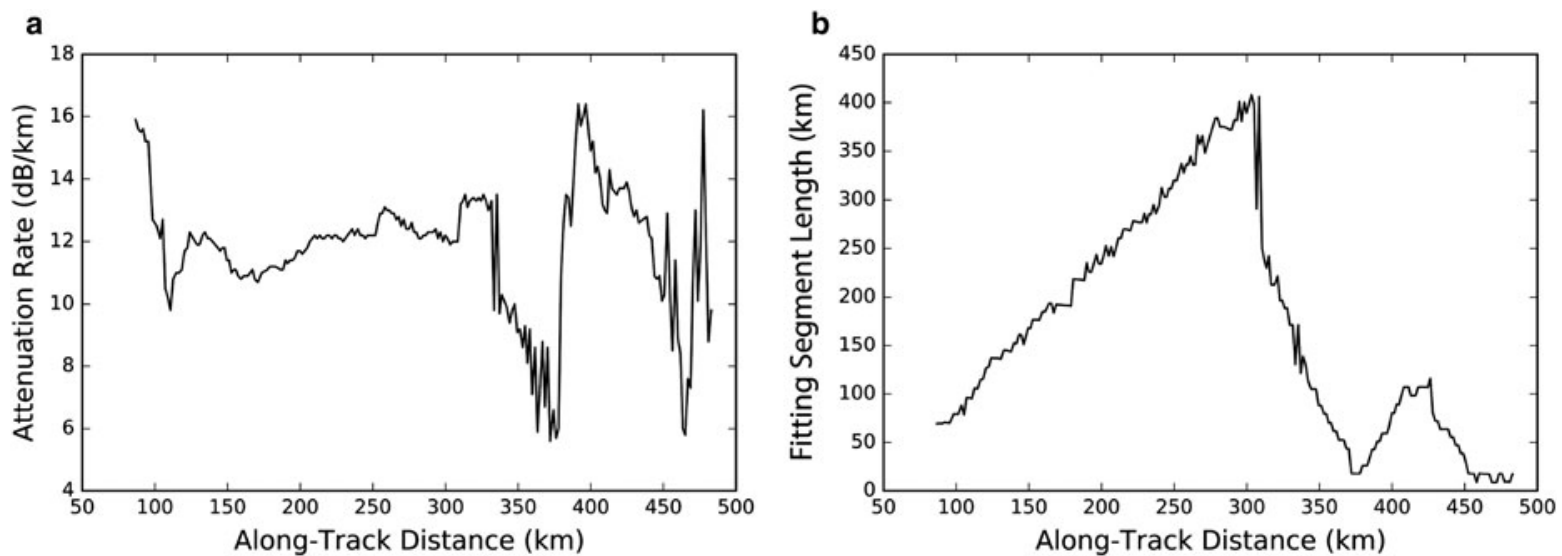

Fig. 3. Adaptively fit (a) estimated attenuation rate and (b) fitting segment lengths the example profile (Fig. 1).
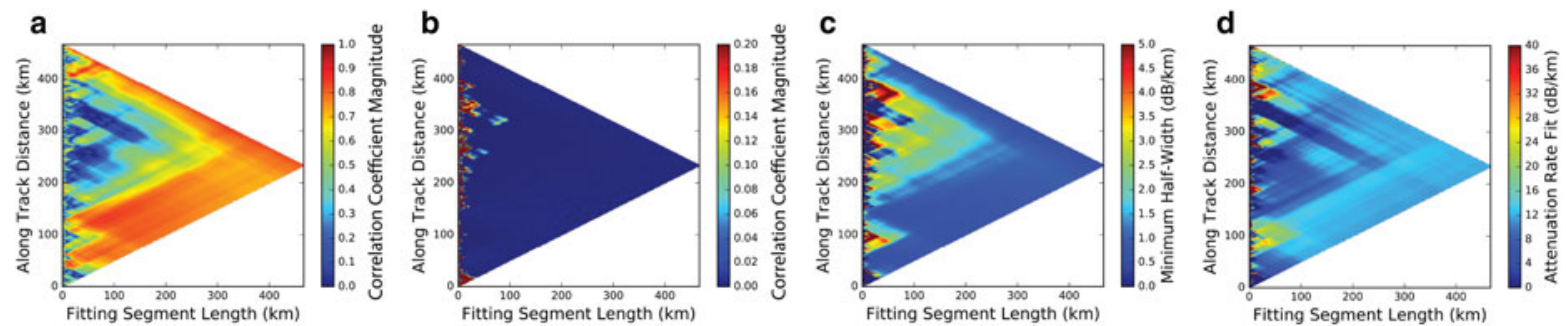

Fig. 4. Results of the method applied to the example profile (Fig. 1), illustrating the effect of fitting window length. (a) correlation coefficient without correction $\left(C_{0}\right)$, (b) minimum correlation coefficient value $\left(C_{\mathrm{m}}\right)$, (c) half-width of the correlation coefficient minimum $\left(\left\langle N_{\mathrm{h}}\right\rangle\right)$, (d) estimated attenuation rate $\left(\left\langle N_{\mathrm{m}}\right\rangle\right)$.
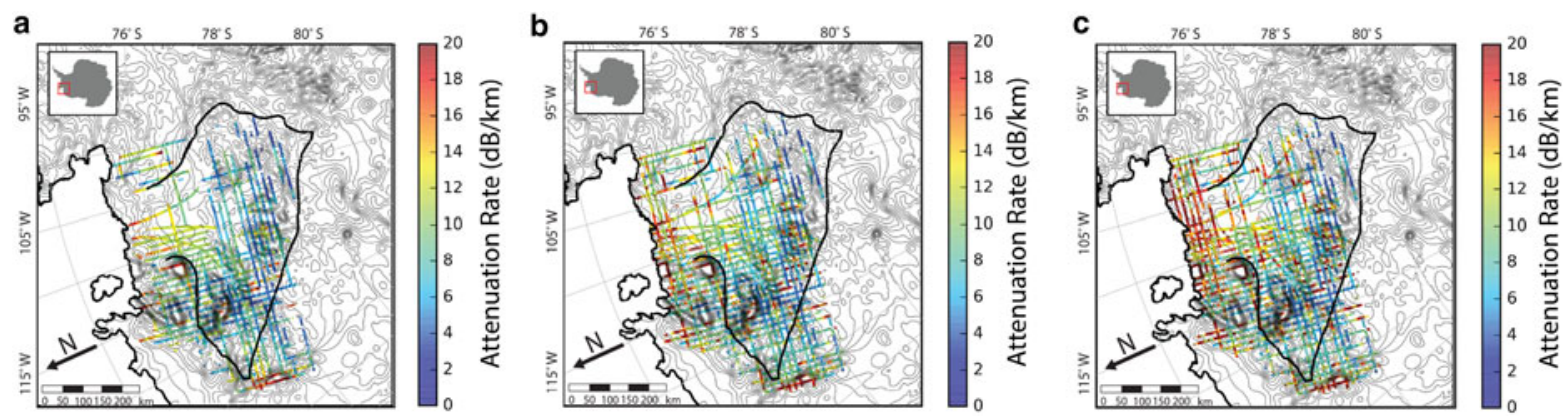

Fig. 5. Estimated attenuation rates for target correlation coefficient half-widths of (a) $\left\langle N_{h}\right\rangle \leq 1 \mathrm{~dB} / \mathrm{km}$, (b) $\left\langle N_{h}\right\rangle \leq 2 \mathrm{~dB} / \mathrm{km}$ and (c) $\left\langle N_{h}\right\rangle \leq 3 \mathrm{~dB} / \mathrm{km}$. Background contours are ice thickness (Fretwell and others, 2013).
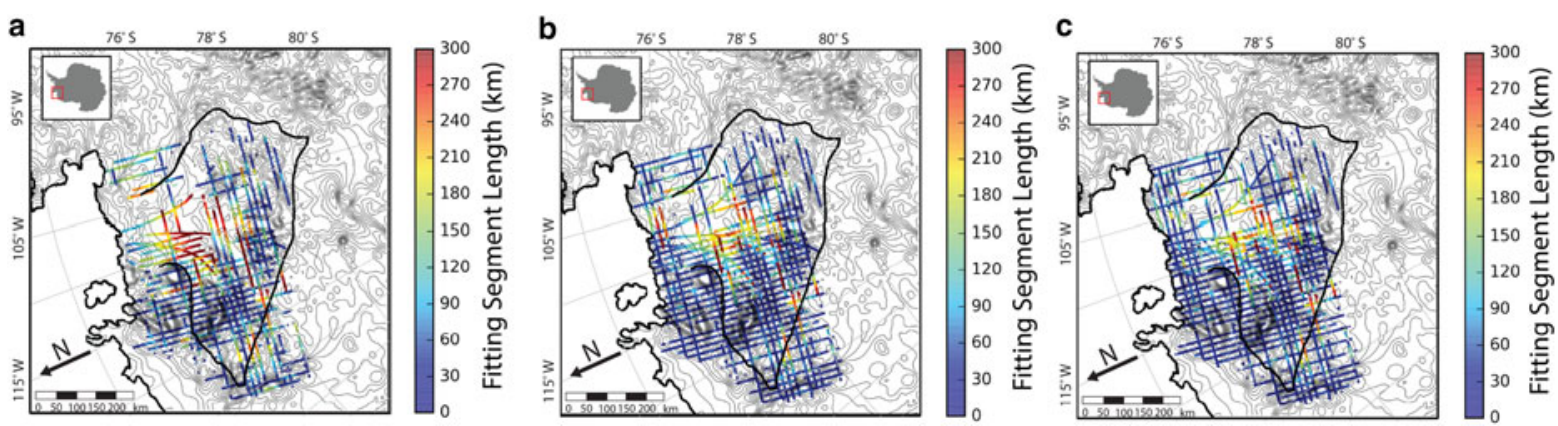

Fig. 6. Fitting segment lengths $(W)$ for target correlation coefficient half-widths of (a) $\left\langle N_{h}\right\rangle \leq 1 \mathrm{~dB} / \mathrm{km}, \quad(b)\left\langle N_{h}\right\rangle \leq 2 \mathrm{~dB} / \mathrm{km}$ and (c) $\left\langle N_{h}\right\rangle \leq 3 \mathrm{~dB} / \mathrm{km}$. Background contours are ice thickness (Fretwell and others, 2013). 
Table 1. Mean $(\mu)$ and standard deviation $(\sigma)$ cross-over errors for the estimated attenuation rates (Fig. 5) using correlation-minimum values of $\left\langle N_{h}\right\rangle \leq 1,2$, and $3 \mathrm{~dB} / \mathrm{km}$

\begin{tabular}{lll}
\hline$\left\langle N_{\mathrm{h}}\right\rangle$ & $\mu$ & $\sigma$ \\
\hline 1 & 3.65 & 2.93 \\
2 & 4.14 & 3.92 \\
3 & 5.12 & 4.50 \\
\hline
\end{tabular}

\section{RESULTS}

In order to create a gridded estimate of englacial rates across the catchment of Thwaites Glacier for comparison with modelled values, we combine the profile-based estimates in Figure 4 by selecting the value at each location with the best radiometric resolution $\left(\left\langle N_{h}\right\rangle\right)$. This allows us to take advantage of the more accurate estimates of Figure 4a without forfeiting the coverage of Figure 4c. This is especially relevant in the high-attenuation regions near the grounding zone and eastern shear margin where the same fractional variation in $\langle N\rangle$ would result in a larger value of $\left\langle N_{h}\right\rangle$ relative to low-attenuation regions. Since the greatest cross-over errors occur near areas of steep relief in basal topography (Fig. 4), we exclude locations with basal slopes $>3.5^{\circ}$ (Fretwell and others, 2013). We then interpolated both the $\left\langle N_{\mathrm{m}}\right\rangle$ and $\left\langle N_{\mathrm{h}}\right\rangle$ results onto a regular $5 \mathrm{~km} \times 5 \mathrm{~km}$ grid, weighting each value by its distance to the grid point using a Gaussian filter with a width of $7.5 \mathrm{~km}$ and scaling the $\left\langle N_{\mathrm{h}}\right\rangle$ values to the corresponding cross-over errors in Table 1. This interpolation results in gridded estimates of both attenuation rates (Fig. 7a) and fitting errors (Fig. 7b) across the catchment.

We compare the observation-based estimates of attenuation rates to values predicted using a numerical ice-sheet model of the same region. For this comparison, we use the Ice Sheet System model (ISSM, Morlighem and others, 2010; Larour and others, 2012). The catchment of Thwaites Glacier (Fig. 1a) is modelled with a $1.5 \mathrm{~km}$ resolution horizontal mesh, extruded into 20 vertical layers. We use an enthalpy-based model (Aschwanden and others, 2012) that includes advection, conduction and deformational heat, and assume the ice to be in thermal steady state (Seroussi and others, 2013). Surface temperatures from the regional atmospheric model RACMO2 (Lenaerts and others, 2012) are imposed at the surface and geothermal flux inferred from magnetic data (Fox Maule and others, 2005) are applied at the base. The full-Stokes equations are used to compute the stress balance. We infer the basal friction to match observed surface velocities (Rignot and others, 2011) using an adjointbased optimization and use it to compute the frictional heat at the base. We interpolate these results onto the same $5 \mathrm{~km}$ grid as the observed attenuation rates and use a temperaturedependent attenuation model for West Antarctica (MacGregor and others, 2007; Matsuoka and others, 2012) to calculate the one-way attenuation rate for the entire ice column (Fig. 8a). Specifically, we use the Matsuoka and others (2012) formulation of the MacGregor and others. (2007) Siple Dome model to calculate the one-way depth-averaged attenuation-rates. We estimate the uncertainty in the modelled attenuationrate as the difference between these values (Fig. 7a) and those computed using a different temperature-dependent attenuation model from Wolff and others (1997) (Fig. 8b). These relatively small uncertainty values (compared with the pattern in Fig. 8a) are conservative estimates since potential errors from assumed ice chemistry or surface temperature values are negligible compared with the difference between models (MacGregor and others, 2015). Therefore, any comparison of the observed (Fig. 7) and modelled (Fig. 8) attenuation-rate patterns can be confidently interpreted as expressions of ice-sheet temperature structure rather than the details of a particular temperature-dependent attenuation-rate model.

Our radar-derived estimates of one-way englacial attenuation rates (Fig. 7) reproduce the catchment-scale pattern of modelled attenuation (Fig. 8) across Thwaites Glacier. Figure 9 shows the difference between the modelled and estimated attenuation values. The greatest differences occur in regions with steep basal topography near the glacier's shear margins (Fig. 9), suggesting that some care should be taken when interpreting attenuation rates in these areas. Where such differences occur, one of two effects is likely at play: first, in some areas liquid basal water or thawed bed, and
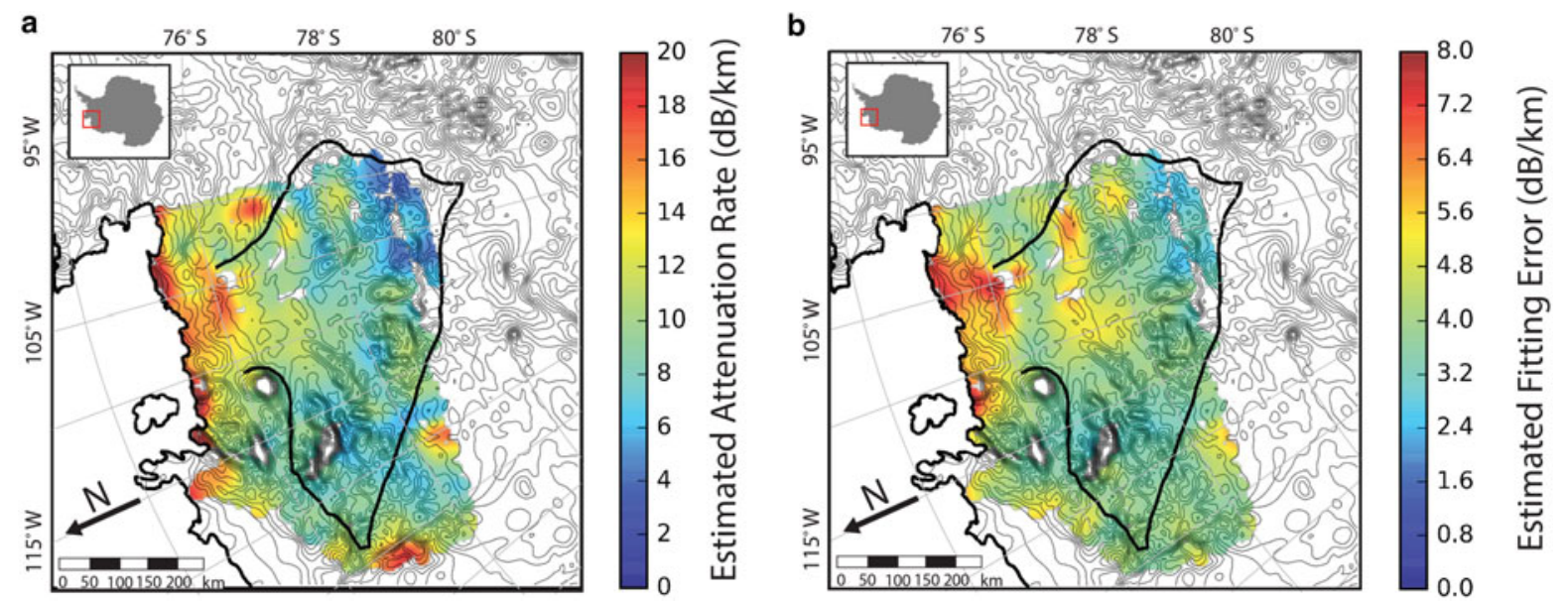

Fig. 7. (a) Gridded attenuation rates from combining the lowest error at each location (Fig. 5) and (b) estimated error for those gridded attenuation rates from scaling the correlation minimum half-widths $\left(\left\langle N_{h}\right\rangle\right)$ to the resulting mean cross-over error $(\mu)($ Table 1$)$. Background contours are ice thickness (Fretwell and others, 2013). 
a

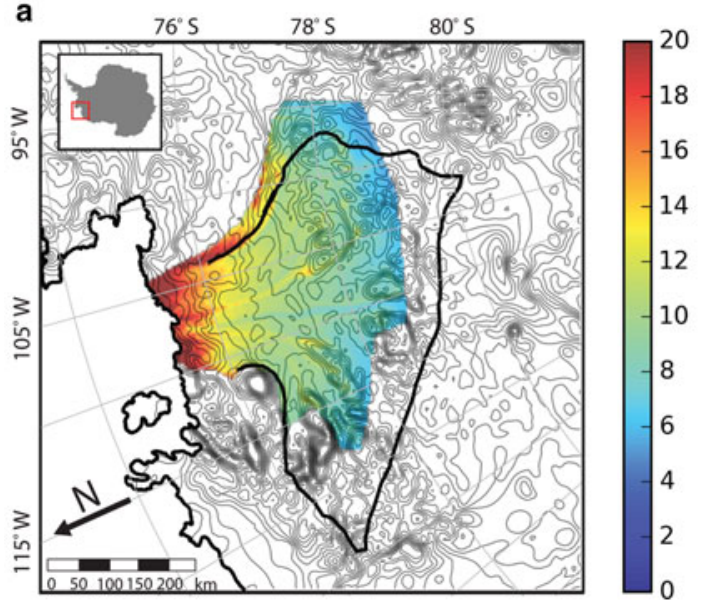

b

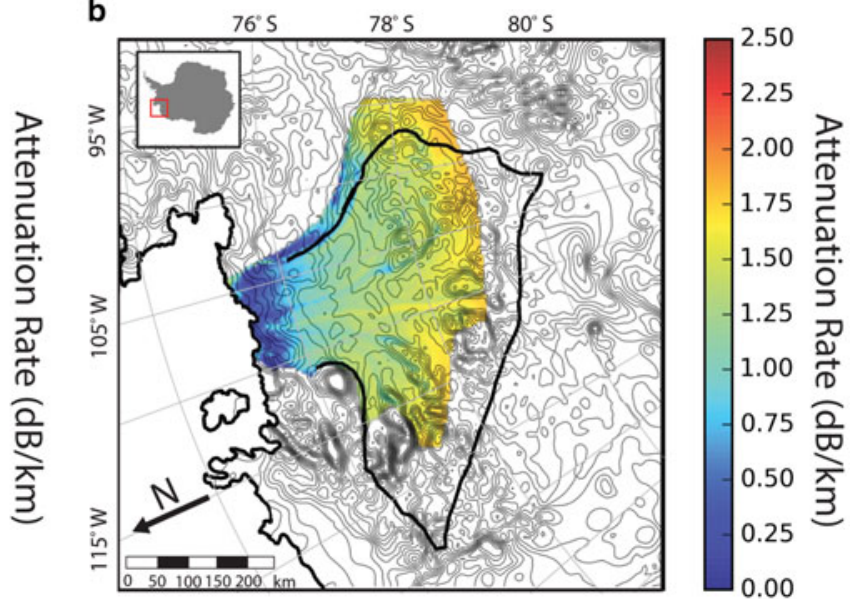

Fig. 8. (a) Modelled attenuation rate using the ISSM numerical ice-sheet model (Larour and others, 2012) and a temperature-dependent attenuation model (MacGregor and others, 2007). (b) Estimated uncertainty in the modelled englacial attenuation rate (Wolff and others, 1997; MacGregor and others, 2015). Background contours are ice thickness (Fretwell and others, 2013).

therefore radar reflectivity, can increase with increasing depth (Schroeder and others, 2016), leading to an under-estimate of attenuation-rates. Second, the opposite effect can also occur in areas where roughness, and therefore scattering losses, increase with ice depth, leading to an over-estimate of attenuation rates (Peters and others, 2005; MacGregor and others, 2013; Young and others, 2016). Because steep slopes result in greater ice-thickness relief (and therefore large $C_{0}$ values) our adaptive-fitting algorithm will tend to expand fitting windows to include them in estimates of nearby attenuation rates (resulting in the observed pattern of over- and under- estimates in Fig. 9). Whatever their sign and cause, even these differences are less than both the attenuation signal itself (Fig. 7a) and the estimated fitting error produced by our technique (Fig. 7b). Overall, we find that our approach successfully captures gridded (Fig. 7) and profile-based (Fig. 5) variations in attenuation rate using only the information in radar bed echoes. Therefore, within the catchment, the pattern of englacial temperature from the ISSM model of Thwaites Glacier is consistent with the pattern of englacial attenuation from radar-sounding observations.

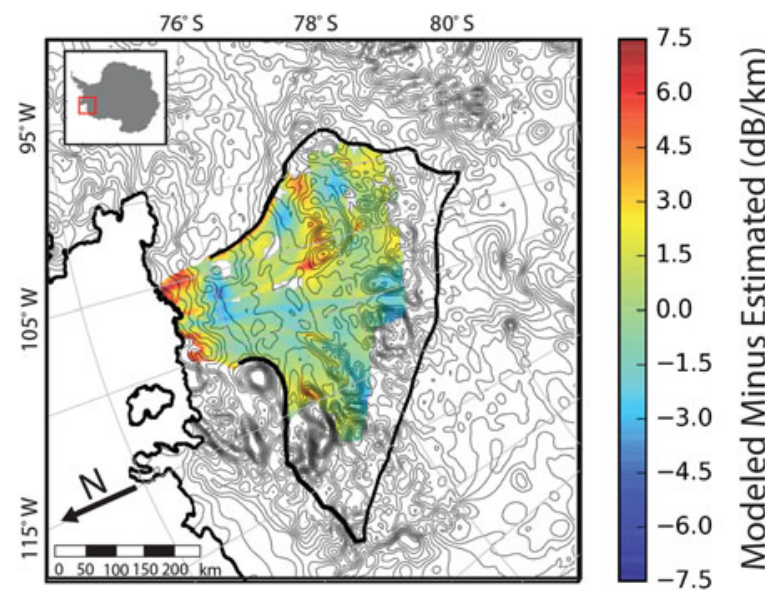

Fig. 9. Difference between estimated (Fig. 7a) and modelled (Fig. 8a) attenuation rates. Background contours are ice thickness (Fretwell and others, 2013).

\section{CONCLUSIONS}

The technique we present directly constrains the spatially variable englacial attenuation rate in glaciers and ice sheets using only bed echoes. This approach can use lines in any orientation and data from any radar sounding system. It probes the full ice thickness (including warm ice at the bottom of the ice column) and operates in the fast-flowing regions of glaciers where the layers are disrupted. We find that this approach is capable of capturing the catchmentscale attenuation-rate structure predicted by the ISSM numerical ice-sheet model. The greatest difference between estimated and modelled values occurs in areas with large slopes in bed topography; however, even this difference falls within the estimated fitting error of the technique. While two-way attenuation rates cannot directly resolve vertical englacial temperature profiles, they place an observational constraint on those profiles through their net effect on signal power. For the first time, this approach provides the radio glaciology community with the capability to place direct observational constraints on the spatial variation in englacial attenuation rates and therefore temperatures using only radar bed echoes. This complements existing layer-based techniques, which can measure vertical gradients in attenuation, but do not probe the entire ice column. Together, these approaches stand to enable observationbased estimates of the entire vertical attenuation and temperature profile across entire ice sheets and glacier catchments.

\section{ACKNOWLEDGEMENTS}

The authors would like to thank N. Holschuh and an anonymous reviewer for their thoughtful comments. D.M.S. was supported by a grant from the NASA Cryospheric Sciences Program. H.S. was supported by grants from the NASA Cryospheric Sciences and Sea Level Rise Programs. W.C. was supported by a NASA Earth and Space Science Fellowship. Part of this work was carried out by the Jet Propulsion Laboratory, California Institute of Technology, under a contract with the National Aeronautics and Space Administration. 


\section{REFERENCES}

Aschwanden A, Bueler E, Khroulev C and Blatter H (2012) An enthalpy formulation for glaciers and ice sheets. J. Glaciol., $\mathbf{5 8}$ (209), 441-457

Barrella T, Barwick S and Salzberg D (2011) Ross Ice Shelf (Antarctica) in situ radio-frequency attenuation. J. Glaciol., 57 (201), 61-66

Bogorodsky VV, Bentley CC and Gudmandsen P (1985) Radiog/aciology, 1st edn. D. Reidel, Dordrecht, Holland

Boithias L (1987) Radiowave propagation. McGraw-Hill, London

Carter SP, Blankenship DD, Young DA and Holt JW (2009) Using radar data to identify the sources and distribution of subglacial water in radar-sounding data: application to Dome C, East Antarctica. J. Glaciol., 55(194), 1025-1040

Chen JL, Wilson CR, Tapley BD, Blankenship DD and Young DA (2008) Antarctic regional ice loss rates from GRACE. Earth Planet. Sci. Lett., 266(1), 140-148

Corr HFJ, Moore JC and Nicholls KW (1993) Radar absorption due to impurities in Antarctic ice. Geophys. Res. Lett., 20(11), 10711074 (doi: 10.1029/93GL01395)

Cuffey KM and Paterson WSB (2010) The physics of glaciers, 4th edn. Elsevier, Burlington, Mass, 693 pp

Dowdeswell JA and Evans S (2004) Investigations of the form and flow of ice sheets and glaciers using radio-echo sounding. Rep. Prog. Phys., 67(10), 1821

Drews $R$ and 6 others (2009) Layer disturbances and the radio-echo free zone in ice sheets. Cyrosphere, 3, 195-203. (doi: 10.5194/ tcd-3-307-2009)

Engelhardt H (2004) Thermal regime and dynamics of the West Antarctic ice sheet. J. Climatol., 39, 85-92

Fox Maule C, Purucker M, Olsen N and Mosegard K (2005) Heat flux anomalies in Antarctica revealed by satellite magnetic data. Science, 309(5733), 464-467

Fujita $S$ and others (2012) Radar diagnosis of the subglacial conditions in Dronning Maud Land, East Antarctica. Cyrosphere, 6, 1203-1219 (doi: 10.5194/tc-6-1203-2012)

Fretwell P and 59 others (2013) Bedmap2: improved ice bed, surface, and thickness datasets for Antarctica. Cyrosphere, 7, 3750393 (doi: 10.5194/tc-7-375-2013)

Gudmandsen P (1971) Electromagnetic probing of ice. In Wait J. Electromagnetic probing in geophysics. Golem Press, Boulder, CO, 321-348

Holt JW and 8 others (2006) New boundary conditions for the West Antarctic Ice Sheet: subglacial topography of the Thwaites and Smith glacier catchments. Geophys. Res. Lett., 33(9), L09502 (doi: 10.1029/2005GL025561)

Jacobel RW, Welch BC, Osterhouse D, Pettersson R and MacGregor JA (2009) Spatial variation of radar-derived basal conditions on Kamb Ice Stream, West Antarctica. Ann. Glaciol., 50(51), 10-16

Jacobel RW and 5 others (2010) A comparison of bed refectivity and velocity in East Antarctica. The Cyrosphere, 4, 447-452 (doi: 10.5194/tc-4-447-2010)

Jordan TM and 7 others (2016) An ice-sheet wide framework for englacial attenuation and basal reflection from ice penetrating radar data. The Cryosph., 10, 1547-1570 (doi: 10.5194/tc-10-1547-2016)

Joughin I and 6 others (2009) Basal conditions for Pine Island and Thwaites Glaciers, West Antarctica, determined using satellite and airborne data. J. Glaciol., 55(190), 245-257

Joughin I, Smith BE and Medley B (2014) Marine ice sheet collapse potentially under way for the Thwaites Glacier Basin, West Antarctica. Science, 344(6185), 735-738

Lenaerts JT, Den Broeke MR, Berg WJ, Meijgaard EV and Kuipers Munneke P (2012) A new, high-resolution surface mass balance map of Antarctica (1979-2010) based on regional atmospheric climate modelling. Geophys. Res. Lett., 39(4), L04501, (doi: 10.1029/2011GL050713)

Larour E, Seroussi H, Morlighem M and Rignot E (2012) Continental scale, high order, high spatial resolution, ice sheet modelling using the Ice Sheet System model (ISSM). J. Geophys. Res., 117 (F01022), (doi: 10.1029/2011JF002140)

MacGregor JA and 5 others (2007) modelling englacial radar attenuation at Siple Dome, West Antarctica, using ice chemistry and temperature data. J. Geophys. Res., 112, F03008 (doi: 10.1029/ 2006JF000717)

MacGregor JA, Matsuoka K, Waddington ED, Winebrenner DP and Pattyn F (2012) Spatial variation of englacial radar attenuation: modelling approach and application to the Vostok fowline. J. Geophys. Res., 117, F03022 (doi: 10.1029/2011JF002327)

MacGregor JA and 7 others (2013) Weak bed control of the eastern shear margin of Thwaites Glacier, West Antarctica. J. Glaciol., 59 (217), 900-912

MacGregor JA and 11 others (2015) Radar attenuation and temperature within the Greenland Ice Sheet. J. Geophys. Res.: Earth Surf., 120(6), 983-1008

Matsuoka K (2011) Pitfalls in radar diagnosis of ice-sheet bed conditions: lessons from englacial attenuation models. Geophys. Res. Lett., 38, L05505 (doi: 10.1029/2010GL046205)

Matsuoka K, Morse D and Raymond CF (2010) Estimating englacial radar attenuation using depth profles of the returned power, central West Antarctica. J. Geophys. Res., 115, F02012 (doi: 10.1029/2009JF001496)

Matsuoka K, MacGregor JA and Pattyn F (2012) Predicting radar attenuation across Antarctica. Earth Planet. Sci. Lett., 359-360, 173-183 (doi: 10.1016/j.epsl.2012.10.018)

Morlighem M and 5 others (2010) Spatial patterns of basal drag inferred using control methods from a full-Stokes and simpler models for Pine Island Glacier, West Antarctica. Geophys. Res. Lett., 37(L14502) (doi: 10.1029/2010GL043853)

Mouginot J, Rignot E and Scheuchl B (2014) Sustained increase in ice discharge from the Amundsen Sea Embayment, West Antarctica, from 1973 to 2013. J. Geophys. Res., 41, 1576-1584 (doi: 10.1002/2013GL059069)

Oswald GKA and Gogineni SP (2008) Recovery of subglacial water extent from Greenland radar survey data. J. Glaciol., $\mathbf{5 4}$ (184), 94-106

Parizek BR and 10 others (2013) Dynamic (in) stability of Thwaites Glacier, West Antarctica. J. Geophys. Res.: Earth Surf., 118(2), 638-655

Peters ME, Blankenship DD and Morse DL (2005) Analysis techniques for coherent airborne radar sounding: application to West Antarctic ice streams. J. Geophys. Res., 110, B06303 (doi: dx. doi.org/10.1029/2004JB003222)

Pollard D, DeConto RM and Alley RB (2015) Potential Antarctic Ice Sheet retreat driven by hydrofracturing and ice cliff failure. Earth Planet. Sci. Lett., 412, 112-121

Pritchard HD, Arthen RJ, Vaughan DG and Edwards LA (2009) Extensive dynamic thinning on the margins of the Greenland and Antarctic ice sheets. Nature, 461(7266), 971-975

Rignot E, Mouginot J and Scheuchl B (2011) Ice flow of the Antarctic ice sheet. Science, 333, 1427-1430 (doi: 10.1126/ science.1208336)

Rignot E, Mouginot J, Morlighem M, Seroussi H and Scheuchl B (2014) Widespread, rapid grounding line retreat of Pine Island, Thwaites, Smith, and Kohler glaciers, West Antarctica, from 1992 to 2011. Geophys. Res. Lett., 41, 3502-3509 (doi: 10.1002/2014GL060140)

Robin GdQ, Evans S and Bailey JT (1969) Interpretation of radio echo sounding in polar ice sheets. Phil. Trans. R. Soc. London A, 265(1166), 437-505

Schoof C (2007) Ice sheet grounding line dynamics: steady states, stability, and hysteresis. J. Geophys. Res., 112, F03S28 (doi: 10.1029/2006JF000664)

Schroeder DM, Blankenship DD, Young DA, Witus AE and Anderson JB (2014) Airborne radar sounding evidence for deformable sediments and outcropping bedrock beneath Thwaites Glacier, West Antarctica. Geophys. Res. Lett., 41, 7200-7208 (doi: 10.1002/ 2014GL061645) 
Schroeder DM, Blankenship DD, Raney RK and Grima C (2015) Estimating subglacial water geometry using radar bed echo specularity: application to Thwaites Glacier, West Antarctica. Geosci. Remote Sens. Lett. IEEE, 3, 443-447

Schroeder DM, Grima C and Blankenship DD (2016) Evidence for variable grounding-zone and shear-margin basal conditions across Thwaites Glacier, West Antarctica. Geophysics, 81(1), WA35-WA43

Seroussi $\mathrm{H}$ and 5 others (2013) Dependence of century-scale projections of the Greenland ice sheet on its thermal regime. J. Glaciol., 59, 1024-1034

Sutterley TC and 7 others (2014) Mass loss of the Amundsen Sea Embayment of West Antarctica from four independent techniques. Geophys. Res. Lett., 41, 8421-8428 (doi: 10.1002/2014GL061940)

Stocker TF and 9 others (2013) IPCC, 2013: climate change 2013: the physical science basis. Intergovernmental Panel on Climate Change, Working Group I Contribution to the IPCC Fifth Assessment Report (AR5) Cambridge Univ Press, New York

Thomas RH and Bentley CR (1978) A modell for Holocene retreat of the West Antarctic Ice Sheet. Quat. Res., 10, 150-170 (doi: 10.1016/0033-5894(78)90098-4)

Tinto K and Bell RE (2011) Progressive unpinning of Thwaites Glacier from newly identified offshore ridge: constraints from aerogravity. Geophys. Res. Lett., 38, L20503 (doi: 10.1029/ 2011GL049026)

Tsai VC, Stewart AL and Thompson AF (2015) Marine ice sheet profiles and stability under Coulomb basal conditions. J. Glaciol., 61, 205-215 (doi: 10.3189/2015JoG14J221)

Weertman J (1974) Stability of the junction of an ice sheet and an ice shelf. J. Glaciol., 13, 3-11

Winebrenner DP, Smith BE, Catania GA, Conway HB and Raymond CF (2003) Radio-frequency attenuation beneath Siple Dome, West Antarctica, from wide-angle and profiling radar observations. Ann. Glaciol., 37, 226-232

Wolff EW, Miners WD, Moore JC and Paren JG (1997) Factors controlling the electrical conductivity of ice from the polar regions: a summary. J. Phys. Chem. B, 101(32), 6090-6094

Wright AP and 10 others (2012) Evidence of a hydrological connection between the ice divide and ice sheet margin in the Aurora Subglacial Basin, East Antarctica. J. Geophys. Res.: Earth Surf., 117, F01033, (doi: 10.1029/2011JF002066)

Young DA, Schroeder DM, Blankenship DD, Kempf SD and Quartini E (2016) The distribution of basal water between Antarctic subglacial lakes from radar sounding: a summary. Phil. Trans. R. Soc. A., 374(2059), 6090-6094, v20140297

MS received 4 March 2016 and accepted in revised form 25 July 2016; first published online 9 September 2016 